The impression left on my mind by these few. cases is that salicylic acid is of very decided value in acute rheumatism, and that the more acute the case the more certain we may be of success by using it in full doses.

\title{
SALICYLIC ACID IN ACUTE RHEUMATISM.
}

BY RALPH C. HUSE, M. D., OF GEORgETOWN.

JAMES F., male, thirty years of age, is subject to repeated attacks of acute rheumatism, during which he has been confined to the bed for periods of several weeks, all the joints being involved, with cardiac complication in the first attack.

While reading an item relative to the treatment of this disorder by salicylic acid, in the JournaL, I was called to treat a fresh attack in the above-mentioned patient.

March 26th, eight P. M. J. F., rheumatism. One knee and the opposite ankle were swollen, hot, and exquisitely tender; tongue creamy; urine showed heavy deposits of urates and coloring matter. Treatment, Dover's powder, five grains once only. Two hours after, two grains salicylic acid, in sugar, hourly until the patient is relieved. Joint to be wrapped in cotton batting.

March 27th. Slept part of night, is less feverish, pulse is slower, below $100^{\circ}$, and the joints are somewhat mobile. Treatment : acid, two grains every two hours; diet, simple toast or gruel ; Dover's powder if necessary to relieve pain, or to induce sleep.

March 28th. Sitting up, joints free from pain and but slightly swollen. $\mathrm{He}$ is able to extend and flex his leg, has some appetite, and urine is perceptibly clearer. To take the rest of the acid, that is, to one drachm.

March 29th. Saw the patient out-of-doors walking with scarcely any difficulty. Rheumatism all gone. Prescribed a tonic and left him.

This cure does not in itself prove much for the acid, but it is the plain history of a patient successfully treated in a remarkably short time, compared with his former attack and results.

\section{SALICYLIC ACID IN ACUTE RHEUMATISM.}

BY D. W. HODGKINS, M. D., OF EAst BROOKFIELD.

APrIL 13th, M. C. G., a young woman of nineteen years, a factory operative, being warm and perspiring freely, sat in an open window until she began to feel chilly. The next day I was called and found her with some fever and complaining of a general aching and soreness, as she expressed it, all through her flesh and bones. Diaphoretics were prescribed. The day after there was more fever, and the left knee was somewhat swollen and painful. She was put on an alka- 